\title{
Virgin Coconut Oil Attenuates Deficits in Rats Undergoing Transient Cerebral Ischemia
}

\author{
Jose Danilo B. Diestro, MD, ${ }^{* 1,2}$ Abdelsimar T. Omar II, MD, ${ }^{* 1}$ Fresthel Monica M. Climacosa, MD, PhD, ${ }^{3}$ \\ Mark Willy L. Mondia, MD, ${ }^{1}$ Czarina Catherine H. Arbis, DVM, ${ }^{4}$ Therese Marie A. Collantes, DVM, MS, ${ }^{4}$ \\ Kathleen Joy O. Khu, MD, ${ }^{1}$ Artemio A. Roxas Jr., MD, ${ }^{1}$ Maria Amelita C. Estacio, DVM, PhD ${ }^{4}$
${ }^{1}$ Department of Neurosciences, College of Medicine and Philippine General Hospital, University of the Philippines Manila, Manila Philippines
${ }^{2}$ Department of Medical Imaging, St. Michael's Hospital, University of Toronto, Toronto, Ontario, Canada ${ }^{3}$ College of Public Health, University of the Philippines Manila, Manila, Philippines
${ }^{4}$ College of Veterinary Medicine, University of the Philippines Los Baños, Los Baños, Laguna, Philippines

\begin{abstract}
Background and Objectives. Neuroprotection agents may help improve the outcomes of large vessel ischemic stroke. This study aims to explore the role of Virgin Coconut Oil (VCO), with its well-documented anti-oxidant properties, in neuroprotection after transient occlusion of the extracranial internal carotid artery in a rat model of stroke.

Methods. Twenty-three Sprague-Dawley rats were randomized into two groups: 1$)$ control group ( $n=11)$ given distilled water, and 2) treatment group ( $n=12)$ given virgin coconut oil at $5.15 \mathrm{ml} / \mathrm{kg}$ body weight for seven days. Subsequently, the rats underwent transient right extracranial internal carotid artery occlusion (EICAO) for 5 minutes using non-traumatic aneurysm clips. At 4 and 24 hours after EICAO, the animals were examined for neurologic deficits by an observer blinded to treatment groups, then sacrificed. Eight brain specimens ( 4 from each group) were subjected to histopathologic examination ( $\mathrm{H} \&$ E staining) while the rest of the specimens were processed using triphenyltetrazolium chloride (TTC) staining to determine infarct size and area of hemispheric edema.
\end{abstract}

Results. VCO treatment significantly improved the severity of neurologic deficit (1.42 \pm 2.31 ) compared to the control distilled water group $(4.09 \pm 2.59) 24$ hours after EICAO. Whereas, infarct size and percent hemispheric edema did not significantly differ between the two groups.

Conclusion. Prophylactic treatment of VCO is protective against EICAO-induced neurologic deficits in a rat model. VCO shows great potential as a neuroprotective agent for large vessel ischemic stroke. However, more studies are necessary to elucidate the neuroprotective mechanisms of VCO therapy in ischemic stroke.

Key Words: virgin coconut oil, stroke, neuroprotection, anti-oxidant, ischemia

*Dr. Diestro and Dr. Omar share primary authorship for this manuscript.

Podium (Oral) presentation and winner of the Best Research Presentation: $17^{\text {th }}$ Singapore International Stroke Conference, October 2018, Singapore; $2^{\text {nd }}$ place in the Department of Neurosciences, Philippine General Hospital Research Contest, Analytical Category, 2018, Manila, Philippines; $1^{\text {st }}$ place in the Philippine Neurological Association Research Contest, Poster Category, November 2018, Iloilo City, Philippines.

Corresponding author: Jose Danilo B. Diestro, MD Department of Neurosciences, Philippine General Hospital University of the Philippines Manila

Taft Avenue, Manila 1000, Philippines

Division of Diagnostic and Therapeutic Neuroradiology

Department of Medical Imaging, St. Michael's Hospital

University of Toronto, Toronto, Ontario, Canada

Email: danni.diestro@gmail.com

\section{INTRODUCTION}

Cerebrovascular disease (CVD) remains one of the most common causes of morbidity and mortality in the world..$^{1-3}$ Almost a third of patients who had a stroke live with longterm disability. ${ }^{4}$ Thrombolytic therapy and mechanical thrombectomy for large vessel ischemic strokes (LVIS) have been proven to minimize a patient's risk for disability when given in a timely fashion. ${ }^{5}$ However, beyond the golden period of these interventions, management is limited to standard care protocols in the acute stroke unit, which include stroke secondary prevention, rehabilitation, and surgery, if warranted. ${ }^{6,7}$

Free radicals are extremely reactive molecules characterized by the presence of unpaired electrons that can alter proteins, nucleic acids, lipids, and extracellular 
molecules. ${ }^{8}$ These reactive species are responsible for the brain parenchymal damage that leads to poor outcomes in LVIS. During ischemia, free radicals form as a result of (1) a decrease in mitochondrial reduction potential, (2) an increase in nicotinamide adenine dinucleotide phosphate (NADPH) oxidase activity in biological membranes, and (3) an increase in the activity of phospholipase $A_{2}$ and cyclooxygenase. ${ }^{9}$ Free radical formation is amplified with the restoration of blood flow to ischemic parts of the brain due to the influx of oxygen, which is a potent substrate for the formation of superoxide. ${ }^{8}$ Reperfusion injury, characterized by further insult to ischemic but salvageable brain tissue after the re-establishment of blood flow, has proven to be one of the major therapeutic targets in the management of secondary insults following LVIS. ${ }^{10}$

Virgin coconut oil (VCO) is defined by the Philippine Coconut Authority (PCA) as the oil obtained from the fresh and mature kernel of coconut by mechanical or natural means, without undergoing chemical refining, bleaching, or deodorizing, and which does not lead to the alteration of the nature of the oil. ${ }^{11} \mathrm{VCO}$ consists of different fatty acids such as caproic acid, caprylic acid, capric acid, palmitic acid, stearic acid, oleic acid, linoleic acid, lauric acid, and myristic acid. Of note, the latter two medium-chain fatty acids are abundant. VCO also contains polyphenols like phenolic acids, ferulic acid, and p-coumaric acid. The biologic effects of VCO are thought to be mediated by its component medium-chain fatty acids and polyphenols. ${ }^{12}$

The anti-oxidant effects of the polyphenols in VCO have been established by both cell culture and animal studies. ${ }^{13-16}$ The number of phenolic acids, ferulic acid, and p-coumaric acid were found to be correlated with the free radical scavenging activity of $\mathrm{VCO}^{14}$ Besides, $\mathrm{VCO}$ was found to reduce lipid peroxidation and increase the activity of superoxide dismutase..$^{13}$

The most studied benefit of VCO supplementation is its effect on the lipid profile i.e. effectively increasing high-density lipoprotein (HDL) levels while decreasing cholesterol and triglyceride levels using established animal models. ${ }^{17,18}$ Two trials involving human subjects, a crossover trial on healthy subjects monitoring HDL levels ${ }^{19}$ and a controlled trial on coronary artery disease patients, ${ }^{20}$ validate the ability of VCO to raise HDL levels.

Studies on the benefits of VCO on neurologic illnesses are limited. Despite this, VCO has been marketed as a food supplement with protective effects against CVD and myocardial infarction and is widely available in health food stores. Thus, the study aims to determine whether VCO can improve clinical outcomes after large-vessel ischemic stroke in a rat model. While VCO has been used in trials involving human participants for Alzheimer's Disease, ${ }^{21}$ we felt that an animal study needed to be done first to give insight into the mechanism of $\mathrm{VCO}$ for neuroprotection in stroke, if any.

\section{MATERIALS AND METHODS}

\section{Ethical Statement}

This protocol was approved by the Institutional Animal Care and Use Committee (IACUC) of the university. All efforts were made to minimize animal suffering and to reduce the number of animals used. Animal care followed the recommendations of the European Convention for the Protection of Vertebrate Animals Used for Experimental and Other Scientific Purposes (Council Directive 86/609/ EEC $)^{22}$ and the Principles of Laboratory Animal Care (NIH Publication Vol 25, No. 28 revised 1996; http://grants. nih.gov/grants/guide/notice-files/not96-208.html).

\section{Housing, Husbandry, and Experimental Animals}

Twenty-three male Sprague-Dawley rats aged eight to ten weeks old and weighing between 250-280 grams were obtained from the hospital laboratory. All experiments were performed at the animal house of the university. Rats were housed individually in standard polycarbonate cages with stainless steel top and kept at $22 \pm 2^{\circ} \mathrm{C}, 30$ to $50 \%$ humidity, at 12 hours/12-hour light-dark cycle and fed ad libitum with commercial pellets and water for seven days before the experimental procedure. The health and behavior of the animals were monitored during the one-week acclimation period.

\section{Study Design and Experimental Procedure}

A complete randomized block design was utilized in the study. Rats were randomly divided into two groups namely: a control group $(n=11)$ given distilled water for 7 days and a treatment group $(n=12)$ given VCO for the same duration. Because a completely randomized design is utilized in this study, the unequal number of rats in each group was tolerated. ${ }^{23}$

Both distilled water and VCO were administered daily for seven days using a stainless steel oral gavage. In a toxicity study on $\mathrm{VCO}^{24}$ the median lethal dose $\left(\mathrm{LD}_{50}\right)$ of $\mathrm{VCO}$ was found to be greater than $36.7 \mathrm{~g} / \mathrm{kg}$ in mice while the oral no adverse effect level (NOAEL) in mice was determined to be $2.3 \mathrm{~g} / \mathrm{kg}$. VCO treatment group was given $\mathrm{VCO}$ once daily for seven days at a dosage of $5.15 \mathrm{ml} / \mathrm{kg}$ body weight, which is equivalent to $4.6 \mathrm{~g} / \mathrm{kg}$ rat using the density of $0.893 \mathrm{~g} / \mathrm{ml} .{ }^{25}$ This dose was equivalent to the recommended human dose of three to four tablespoons per day. ${ }^{24}$

An hour after the last administration of VCO or distilled water, extracranial internal carotid artery occlusion (EICAO) was done on both $\mathrm{VCO}$ and the control rats as outlined by Desamero et al. ${ }^{26} \mathrm{~A}$ treatment-blinded veterinarian with experience in EICAO performed the procedure. The rats were anesthetized intraperitoneally with a cocktail of ketamine at $90 \mathrm{mg} / \mathrm{kgBW}$ and xylazine at $9 \mathrm{mg} / \mathrm{kgBW}$.

The right ventral neck and throat region were shaved and sterilized with alcohol and povidone-iodine. The rats were placed supine with a four-point restraint on a 
wooden operating block with a disposable sterile drape. A $2-\mathrm{cm}$ ventral midline incision was made using a scalpel. The right internal carotid artery (RICA) was dissected free from the vagus nerve and surrounding tissues. The RICA was temporarily clipped for 5 minutes using a microvessel clip (RWD, San Diego) to induce transient ischemia. The clip was removed and the incision site was closed with 3-0 absorbable suture material (Polyglactin 910, Ethicon Inc., New Jersey). The operative site was sterilized again after closure. Heating lamps and heating pads were provided during the entire procedure to prevent hypothermia and to promote faster recovery from general anesthesia.

The determination of the neurologic deficit score (NDS) was made at two-time points, 4 hours, and 24 hours after EICAO, by an observer who was blinded to the treatment assignment. The rats were placed on a table and videotaped during assessment for neurologic deficits. The following maneuvers were performed on the rats: letting the rat roam freely on the table, applying a gentle lateral push behind the rat's shoulders, and suspending the rat above the table for a few seconds. After the maneuvers and observations were performed, the rats were graded on an 8-point NDS scale (Table 1). The maneuvers and the NDS scale were used by Desamero et al., ${ }^{26}$ and were an adaptation from an earlier study by Bederson et al. ${ }^{27}$ After the assessment for neurologic deficits, the rats were euthanized by intraperitoneal injection of pentobarbital sodium at a dose of $150 \mathrm{mg} / \mathrm{kg}$ body weight.

Table 1. Neurologic Deficit Score 26

\begin{tabular}{cl} 
Score & \multicolumn{1}{c}{ Description } \\
0 & No neurologic deficit \\
1 & Left forelimb flexion when suspended by the tail or \\
& failure to extend the left paw fully \\
2 & Left shoulder adduction when suspended by the tail \\
3 & Reduced resistance to lateral push toward the left side \\
4 & Spontaneous movements in all directions with circling to \\
& the left exhibiting only if pulled by the tail \\
5 & Circling or walking spontaneously only to the left \\
6 & Walking only when stimulated \\
7 & No response to stimulation \\
8 & Stroke related death \\
\hline
\end{tabular}

\section{Tissue Processing}

Brain tissue samples from randomly selected rats from each group were collected by a treatment-blinded pathologist. Four brains from each group were processed using routine histopathological techniques (10\% buffered neutral formalin fixation) to prepare $5 \mu \mathrm{m}$ thick, coronal brain sections at the level of the bregma. Staining with hematoxylin and eosin was done. Histopathological examination was performed using stereo and digital microscopes (Olympus ${ }^{\circledR}$ Tokyo). Photomicrographs were taken using Evos $^{\circledR}$ FL Imaging System (Fisher Scientific, Pittsburgh, PA). All specimens were analyzed by a veterinarian specializing in animal pathology who was blinded to the treatment assignments.
The rest of the brain samples were sliced in 2 -mm-thick coronal sections and stained with $2 \%$ 2,3,5-triphenyltetrazoliumchloride (TTC) (Sigma Aldrich, St. Louis, Missouri) for 10 minutes in the dark at $37{ }^{\circ} \mathrm{C}$ for gross morphologic analysis. Sections were scanned and analyzed using ImageJ software version 1.51s (http://rsbweb. nih.gov/ij/). Infarcted regions were visualized as poorly staining regions in contrast to the red-orange-stained areas of normal brain tissue. The infarcted and the total brain areas were traced manually in the loaded images. The number of pixels in the selected area was determined using the menu option Analyze then Measure. ${ }^{28}$ The computed values were recorded and the process repeated on subsequent images. Infarct percentage was calculated as the sum of the areas of an infarcted region divided by the total brain area and multiplying by $100 .{ }^{29}$ For determination of the area of brain edema, the ipsilateral (injured) and contralateral (uninjured) hemispheres were manually traced and the pixel number was computed as previously described. Ipsilesional hemisphere swelling was calculated by analyzing the difference in the size of the ipsilateral and contralateral hemispheres using the formula ${ }^{30}$ :

$$
\begin{gathered}
\text { Ipsilateral Hemispheric } \\
\text { Edema Percentage }
\end{gathered}=\frac{\text { Ipsilateral area }- \text { Contralateral area }}{\text { Contralateral area }} \times 100
$$

A single observer blinded to treatment assignment performed the analysis described.

The remains of all experimental animals were packed in polythene bags before disposal. They were buried four feet below the ground away from any water pipelines and covered with lime and disinfectants.

\section{Statistical Analysis}

The results were expressed as mean \pm standard deviation. Non-parametric test for two samples Wilcoxon rank-sum (Mann Whitney) test was used to compare NDS, infarct percentage, and percent hemispheric edema. All statistical analyses were performed using GraphPad Prism 7. P-value of less than 0.05 was considered statistically significant.

\section{RESULTS}

\section{Neurologic Deficits}

One rat from each treatment arm died after surgery $(\mathrm{NDS}=8)$. All rats $(\mathrm{n}=23)$ were included in the analysis. The results of the neurologic testing done at 4 hours and 24 hours after EICAO are summarized and illustrated in Figure 1. Two-sample Wilcoxon rank-sum (Mann Whitney) test showed that there was no significant difference between NDS of the control group $(5.72 \pm 1.35)$ and the VCO treatment group $(5.17 \pm 1.03) 4$ hours after occlusion $(p=0.28)$. However, the severity of neurological deficit was significantly reduced in the VCO treatment group (1.42 \pm 2.31) compared to the control group $(4.09 \pm 2.59) 24$ hours after occlusion $(\mathrm{p}=0.01)$ (Figure 1$)$. 


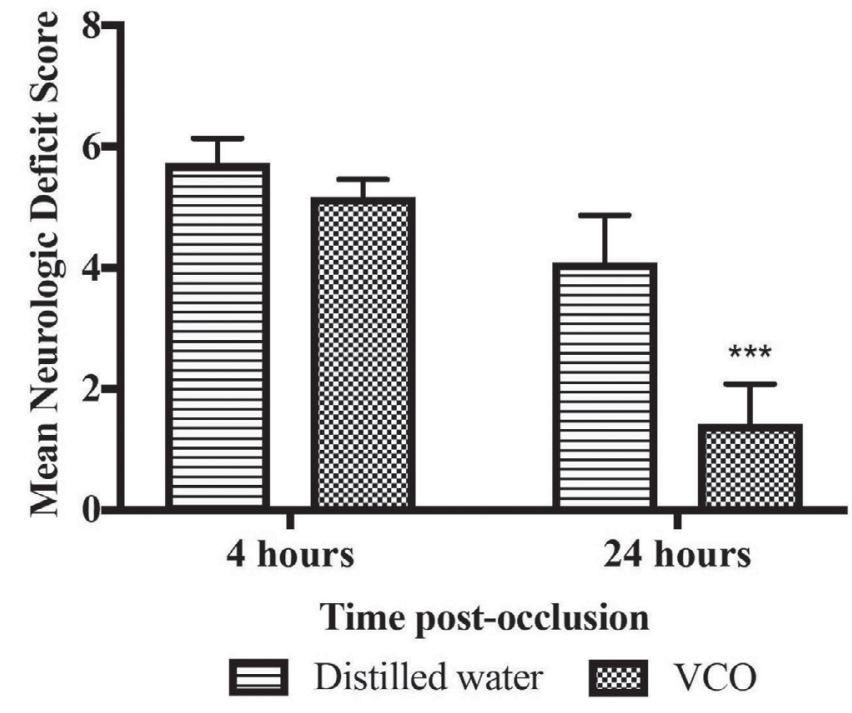

Figure 1. Neurologic deficit scores (NDS) of the rats in the distilled water control and virgin coconut oil (VCO) treatment groups were observed during 4 and 24 hours post-occlusion of the right internal carotid artery (RICA). A significant reduction in NDS of the rats receiving $\mathrm{VCO}$ was observed 24 hours postocclusion. $^{* * *}-p<0.05$

\section{Histopathologic Analysis}

Coronal sections of brain tissue at the level of the bregma did not show any sharp demarcation between ischemic and non-ischemic areas for both groups at low magnification. At high magnification, however, histopathological changes signifying early neuronal injury were seen in both groups. Figure 2 shows the presence of red neurons characterized as eosinophilic cells with pyknotic nuclei, increased perinuclear space, and neuropil microvacuolation. These cells were seen in both the contralateral and ipsilateral neocortical layers in both treatment groups, and are consistent with the histopathologic sequelae of transient ischemia and hypoxia-induced by EICAO and subsequent euthanasia.

\section{Staining with 2,3,5-triphenyltetrazoliumchloride}

The discrete areas showing the absence of TTC staining that characterizes core infarct ${ }^{31}$ in protocols employing MCA occlusion were not observed in our study specimens. This is likely due to the duration of EICAO in the current study - five minutes - which was significantly shorter than the hour-long occlusion of the MCA in other studies. ${ }^{31}$ Nonetheless, poorly staining regions ipsilateral to the side of the EICAO were noted. Figure 3 shows representative specimens from both groups that confirm ischemic changes in the right ICA territory after EICAO.

Delineation of infarcted region and determination of hemispheric edema was done. Gross morphologic analysis showed no difference $(p=0.694)$ in the infarct size between the control group $(50.77 \pm 33.49 \%)$ and the VCO treatment group $(55.07 \pm 32.93 \%)$. Although a trend toward less edema was noted in the VCO treatment group $(0.06 \pm 18.07 \%)$ compared to the control $(10.67 \pm 36.7 \%)$, this was not statistically significant $(\mathrm{p}=0.548)$ (Figure 4).

\section{DISCUSSION}

Treatment with VCO conferred a protective effect against neurologic deficits in a rat model of LVIS. The decrease in NDS scores seen on assessment $24 \mathrm{~h}$ after occlusion in the VCO treatment group which was not seen during the 4-hour assessment suggests that VCO helps reverse ischemic insults to the brain following EICAO. This is likely due to its antioxidant properties.

Due to its high metabolic activity and relatively sparse endogenous antioxidant enzymes, neurons are particularly susceptible to oxidative damage that occurs after periods of ischemia. ${ }^{9}$ This increased production of free radicals following ischemic injury has been unequivocally confirmed in rat models of stroke. ${ }^{8}$ The administration of known anti-oxidants such as a-phenyl-N-tert-butyl nitrone (PBN) and MCI-186 has also been shown to reduce infarct volumes in animal studies. ${ }^{32} \mathrm{VCO}$, with its known antioxidant properties, may act similarly. ${ }^{13-16}$

The use of transient EICAO pioneered by a previous neuroprotection study ${ }^{26}$ requires less time and technical skill compared to other established stroke models such as the intraluminal MCA, craniotomy, photothrombolysis, endothelin-I, and embolic stroke models. ${ }^{33}$ However, the effects of the EICAO on the TTC stained specimens were not as remarkable as that of the commonly used MCAO model, ${ }^{31}$ as seen in our study. Both the TTC stained brain specimens and histopathologic slides demonstrated findings of ischemic injury after EICAO. The histopathologic sequela of red neurons noted to be distributed on both cerebral cortices seen after EICAO in this study was similar to the findings of Desamero et al. ${ }^{26}$

The percentages of the infarcted and edematous regions determined with the use of TTC staining and image analysis did not vary between the groups at 24-hour reperfusion. The mismatch between the observed improvement in NDS scoring with the treatment group and the non-significant difference in histologic analysis between the two groups is likely due to the phenomenon of penumbra. A penumbra is potentially salvageable hypoxic brain tissue that surrounds the core infarct after intracranial vessel occlusion and can remain up to 24 hours after ictus. ${ }^{34,35}$ The ischemic penumbra is a region of brain tissue that is functionally impaired but remains structurally intact, and may thus cause neurologic deficits. ${ }^{9}$ Since the stains were not sensitive for penumbra, a non-visualized penumbra in the control group may have accounted for the higher NDS scores.

There is a paucity of data on the use of VCO for neurologic conditions. A search on Pubmed using the term "Virgin Coconut Oil" retrieved 97 search items while the 

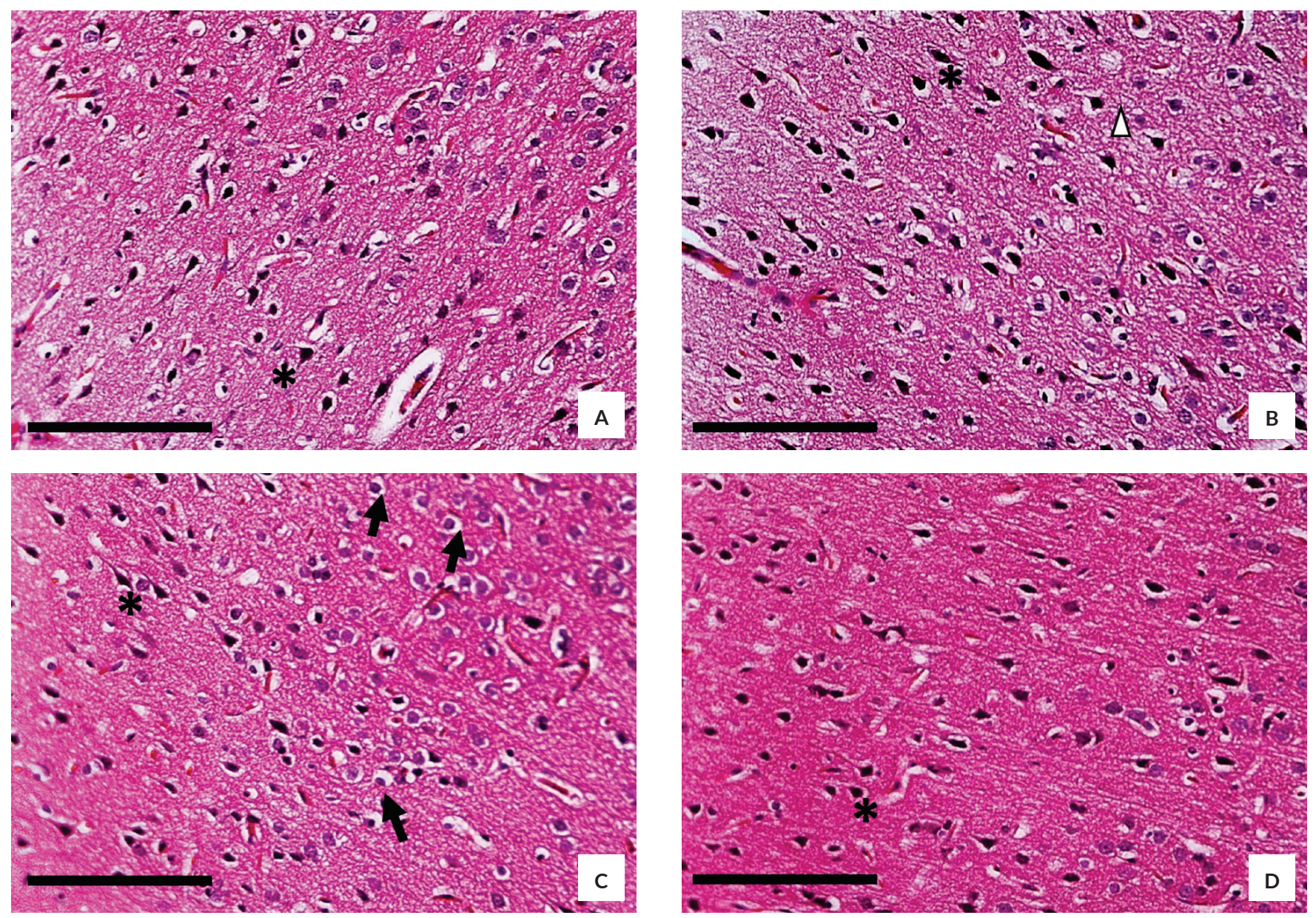

Figure 2. Histopathologic sections of the brains from both treatment and control groups showing red neurons $\left({ }^{*}\right)$, increased perinuclear space (arrow), and neuropil microvacuolation (arrowhead). (A) Ipsilateral (right) neocortex of a rat from the VCO treatment group; (B) Contralateral (left) neocortex of a rat from the VCO treatment group; (C) Ipsilateral (right) neocortex of a rat from the distilled water control group; (D) Contralateral (left) neocortex of a rat from the distilled water control group (400x magnification, $\mathrm{H} \& \mathrm{E}) \mathrm{Bar}=200 \mu \mathrm{m}$

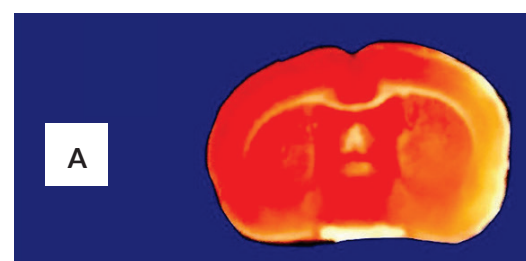

L

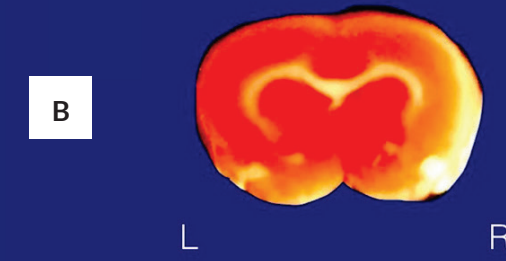

$\mathrm{R}$

R

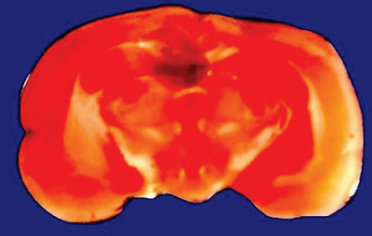

$\mathrm{R}$

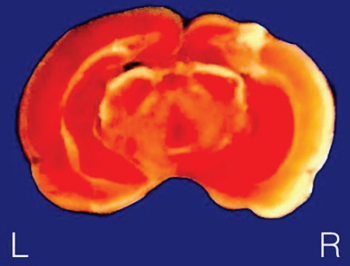

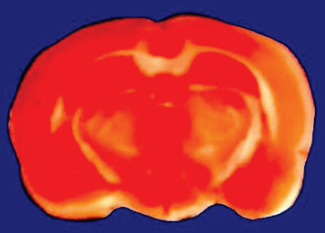

L

$\mathrm{R}$

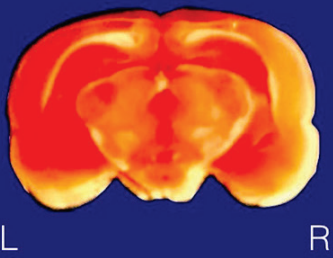

Figure 3. Representative brain specimens from the (A) VCO treatment and (B) Distilled water control groups after staining with 2,3,5-triphenyltetrazolium chloride. The neocortex stained red-orange represents non-infarcted brain tissue while the yellow areas of poorly staining neocortex represent infarcted brain tissue corresponding to the area supplied by the right ICA. 
Table 2. Studies using VCO for neurologic conditions

\begin{tabular}{|c|c|c|c|c|}
\hline Author & Population and design & Neurologic Domain & Intervention and Methods & Results \\
\hline $\begin{array}{l}\text { Rahim et al. }{ }^{38} \\
2017\end{array}$ & $\begin{array}{l}\text { Wistar Rats; Randomized } \\
\text { controlled trial }\end{array}$ & Memory & $\begin{array}{l}\text { VCO before Morris Water } \\
\text { Maze test }\end{array}$ & $\begin{array}{l}\text { VCO had significant memory } \\
\text { enhancing properties }\end{array}$ \\
\hline $\begin{array}{l}\text { Melo et al. }{ }^{37} \\
2018\end{array}$ & $\begin{array}{l}\text { Wistar rats: Randomized } \\
\text { controlled trial }\end{array}$ & Epilepsy & $\begin{array}{l}\text { Ketogenic diet based on VCO } \\
\text { after induction of pilocarpine- } \\
\text { induced status epilepticus }\end{array}$ & $\begin{array}{l}\text { VCO had no effect on frequency } \\
\text { and duration of seizures }\end{array}$ \\
\hline $\begin{array}{l}\text { Hu Yang et al. }{ }^{21} \\
2015 \\
\text { (Article in Spanish) }\end{array}$ & $\begin{array}{l}\text { Alzheimer's disease patients; } \\
\text { Pilot randomized } \\
\text { controlled trial }\end{array}$ & Memory; Dementia & $\begin{array}{l}\text { VCO before cognitive } \\
\text { assessment with Mini-examen } \\
\text { cognoscitivo }\end{array}$ & $\begin{array}{l}\text { Significant decline in scores in the } \\
\text { VCO group }\end{array}$ \\
\hline $\begin{array}{l}\text { Mirzaei et al. }{ }^{39} \\
2018\end{array}$ & $\begin{array}{l}\text { Wistar Rats; Randomized } \\
\text { controlled trial }\end{array}$ & Memory; Dementia & $\begin{array}{l}\text { VCO in Wistar rats with beta- } \\
\text { amyloid induced toxicity; used } \\
\text { Morris maze master test and } \\
\text { passive avoidance learning }\end{array}$ & $\begin{array}{l}\text { VCO groups did better in memory } \\
\text { and learning tests }\end{array}$ \\
\hline $\begin{array}{l}\text { Da Silva et al. }{ }^{40} \\
2018\end{array}$ & $\begin{array}{l}\text { Wistar Rats; Randomized } \\
\text { controlled trial }\end{array}$ & Memory; behaviour & $\begin{array}{l}\text { VCO with exercise before } \\
\text { object recognition test and } \\
\text { open field test }\end{array}$ & $\begin{array}{l}\text { VCO with exercise ameliorated } \\
\text { the effects of stress on anxiety } \\
\text { and memory }\end{array}$ \\
\hline $\begin{array}{l}\text { Nafar et al. }{ }^{41} \\
2017\end{array}$ & $\begin{array}{l}\text { Cortical neuron cultures; } \\
\text { Randomized controlled trial }\end{array}$ & Memory & $\begin{array}{l}\text { VCO in cultured neurons with } \\
\text { beta-amyloid }\end{array}$ & $\begin{array}{l}\text { VCO decreases beta amyloid- } \\
\text { induced decrease in cell viability }\end{array}$ \\
\hline $\begin{array}{l}\text { Ching et al. }{ }^{36} \\
2017\end{array}$ & $\begin{array}{l}\text { Alzheimer's disease patients; } \\
\text { Randomized double } \\
\text { blind controlled trial }\end{array}$ & Memory; Dementia & $\begin{array}{l}\text { VCO given and memory } \\
\text { assessed until } 6 \text { months }\end{array}$ & $\begin{array}{l}\text { VCO did not improve cognition or } \\
\text { behavior in } A D \text { patients }\end{array}$ \\
\hline Diestro et al. & $\begin{array}{l}\text { Sprague-Dawley rats; } \\
\text { Randomized controlled trial }\end{array}$ & Stroke & $\begin{array}{l}\text { VCO before transient EICAO; } \\
\text { neurologic deficits assessed } \\
\text { post-occlusion }\end{array}$ & $\begin{array}{l}\text { Significantly better Neurologic } \\
\text { Deficit Scale scores in the } \\
\text { VCO group }\end{array}$ \\
\hline
\end{tabular}

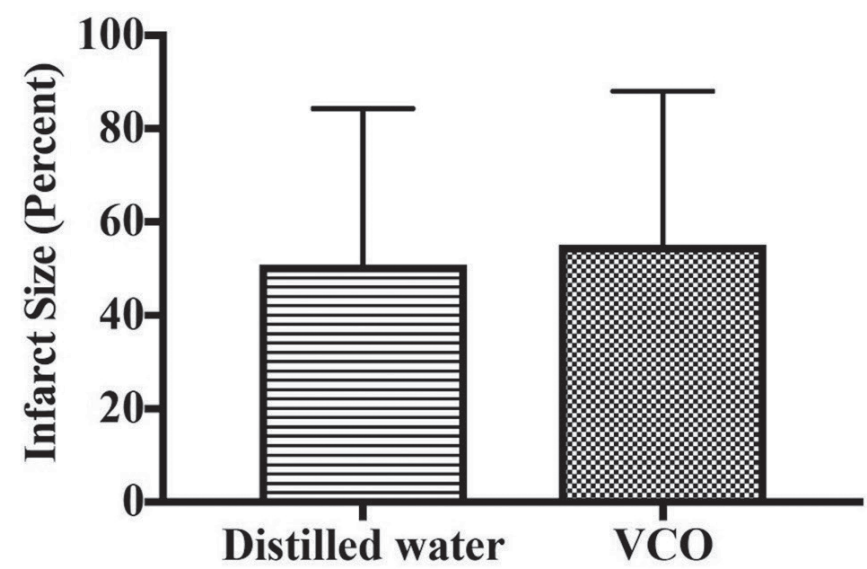

A

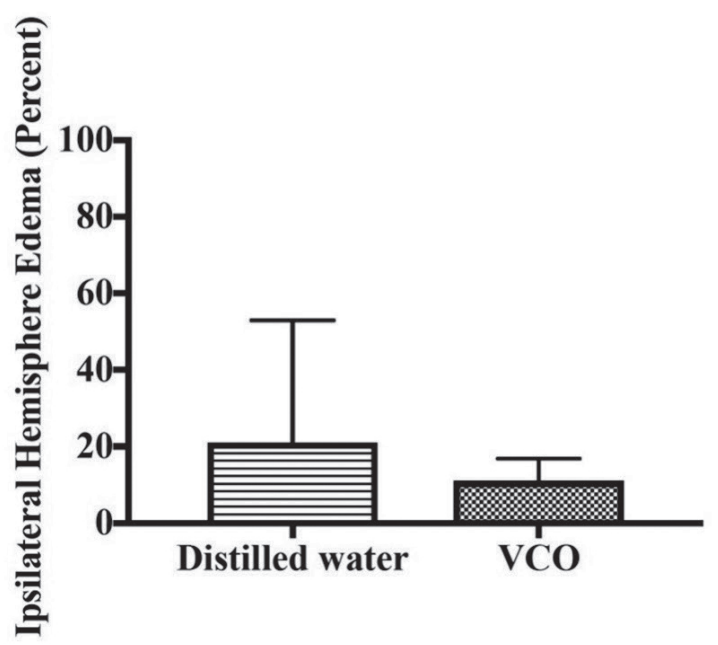

Figure 4. Calculated percentages of $(A)$ infarct size and (B) hemispheric edema of rats in the distilled water control and VCO treatment groups. Differences in percentages between the two groups did not attain statistical significance.

same search on Scopus yielded 303 items. After thoroughly reviewing the abstracts and titles of all the articles, only 7 articles related to the use of VCO in neurological disorders. These studies are summarized along with our research in Table 2. Six of the studies evaluated the potential role of $\mathrm{VCO}$ in the prevention and treatment of memory loss, with two studies being pilot clinical studies involving Alzheimer's disease patients. ${ }^{21,36}$ None of the studies dealt with stroke; thus, our study is the first to explore the possible benefits of the use of $\mathrm{VCO}$ supplementation for CVD. In terms of outcome, only two studies failed to show neuroprotective properties of VCO, the epilepsy study ${ }^{37}$ and one pilot study on Alzheimer's disease. ${ }^{36}$ 'The rest of the studies, including our own, demonstrated improvement in the measured neurologic parameters.

Currently, the 2018 American Heart Association and American Stroke Association Guidelines for the management of acute ischemic stroke do not recommend the use of neuroprotection agents. Numerous agents, such as citicoline, ${ }^{42}$ cerebrolysin, ${ }^{43}$ and magnesium ${ }^{44}$, had promising results in animal studies, but have failed to translate to improvement in clinical outcomes. Thus, the search for a neuroprotective agent that can augment the effects of the current standard medical treatment and mechanical 
reperfusion, as well as address the treatment gap for stroke patients who are ineligible for these methods, continues. VCO, with its anti-oxidant properties, holds great promise to become such a neuroprotection agent for LVIS.

The main limitation of this study is that VCO was only given as a supplement before occlusion of the extracranial RICA. As a result, the possible therapeutic effects of VCO after occlusion of the artery was not evaluated. The latter scenario can translate to an even bigger clinical role for $\mathrm{VCO}$ because it gives $\mathrm{VCO}$ a possible adjuvant therapeutic role rather than being relegated to a dietary supplement role.

Another limitation of this study is the use of a newly developed stroke model. While the new model holds great promise, further studies should be done on improving the model and the histopathologic analyses that go with it. Lastly, the use of more complex staining methods and biochemical analyses ${ }^{45}$ such as pimonidazole to visualize penumbra tissue ${ }^{34}$ could help determine the mechanism behind the improved NDS scores in the treatment group.

EICAO model of stroke in rats is an appealing alternative as it is a faster and relatively simpler technique to perform compared to other established animal stroke models. Although histologic and morphologic assessment of brain tissue did not vary for the control and VCO groups, statistically significant improvement in neurologic deficit scores was observed in the VCO group 24 hours after arterial occlusion. Recommendations for future studies include the use of VCO after the induction of the occlusion, the inclusion of other biochemical and histopathologic techniques in the analysis of ischemic brain parenchyma, and further refinement of the EICAO model of stroke. Performing the study using the more established MCAO model of stroke which allows for a longer occlusion time may also yield more robust data. More studies to elucidate the neuroprotective mechanisms and efficacy of VCO for LVIS are needed.

\section{Statement of Authorship}

$\mathrm{JD}, \mathrm{AO}$ - Conception, design

JD, AO, FC, MM, CA, TC, KOK, AR, ME - Acquisition of data, analysis of data

JD, AO, FC, TC, ME - Drafting the article

JD, AO, FC, MM, CA, TC, KOK, AR, ME - Critically revising the article

TC, AR, ME - Study supervision

\section{Author Disclosure}

All authors declare no conflicts of interest. The authors alone are responsible for the content and writing of this paper.

\section{Funding Source}

The paper received research grants from the Philippine Neurological Association (2017) and the BRAIN foundation of the Philippines (2017).

\section{Data Availability Statement}

The raw data supporting the conclusions of this manuscript will be made available by the authors, without undue reservation, to any qualified researcher.

\section{REFERENCES}

1. World Health Organization: the top 10 causes of death [Internet]. 2017 [cited 2017 Aug 27]. Available from: http://www.who.int/ mediacentre/factsheets/fs310/en/.

2. Dans AL, Morales DD, Velandria FV, Abola MTB, Roxas Jr. A, Punzalan FER, et al. National Nutrition and Health Survey (NNHes): atherosclerosis- related diseases and risk factors. Philipp J Intern Med. 2005; 43(3):103-15.

3. Sy RG, Morales DD, Dans AL, Paz-Pacheco E, Punzalan FER, Abelardo NS, et al. Prevalence of atherosclerosis-related risk factors and diseases in the Philippines. J Epidemiol. 2012;22(5):440-7. doi:10.2188/jea.JE20110095.

4. Robinson T, Zaheer Z, Mistri AK. Thrombolysis in acute ischaemic stroke: an update. Ther Adv Chronic Dis. 2011 Mar; 2(2):119-31. doi:10.1177/2040622310394032.

5. National Institute of Neurological Disorders and Stroke rt-PA Stroke Study Group. Tissue plasminogen activator for acute ischemic stroke. N Engl J Med. 1995 Dec; 333(24):1581-7. doi:10.1056/ NEJM199512143332401.

6. Emberson J, Lees KR, Lyden P, Blackwell L, Albers G, Bluhmki $\mathrm{E}$, et al. Effect of treatment delay, age, and stroke severity on the effects of intravenous thrombolysis with alteplase for acute ischaemic stroke: a meta-analysis of individual patient data from randomised trials. Lancet. 2014 Nov; 384(9958):1929-35. doi:10.1016/S01406736(14)60584-5.

7. Goyal M, Menon BK, van Zwam WH, Dippel DWJ, Mitchell PJ, Demchuk AM, et al. Endovascular thrombectomy after large-vessel ischaemic stroke: a meta-analysis of individual patient data from five randomised trials. Lancet. 2016 Apr; 387(10029):1723-31. doi:10.1016/S0140-6736(16)00163-X.

8. Schmidley JW. Free radicals in central nervous system ischemia. Stroke. 1990 Jul; 21(7):1086-90. doi: 10.1161/01.str.21.7.1086.

9. Bretón RR, Rodríguez JCG. Excitotoxicity and oxidative stress in acute ischemic stroke. In: Rodríguez JCG, ed. Acute Ischemic Stroke. Rijeka, Croatia: InTech; 2012. pp. 30-58. doi:10.5772/1438

10. Pan J, Konstas A-A, Bateman B, Ortolano GA, Pile-Spellman J. Reperfusion injury following cerebral ischemia: pathophysiology, MR imaging, and potential therapies. Neuroradiology. 2007 Feb; 49(2):93-102. doi:10.1007/s00234-006-0183-z

11. Philippine Coconut Authority coconut processing technologies: virgin coconut oil processing [Internet]. 2014 [cited 2016 Feb 27]. Available from: http://pca.da.gov.ph/pdf/techno/virgin_coconut_oil. pdf.

12. Marina AM, Che Man YB, Amin I. Virgin coconut oil: emerging functional food oil. Trends Food Sci Technol. 2009 Oct; 20(10):481-7. doi:10.1016/j.tifs.2009.06.003

13. Yeap SK, Beh BK, Ali NM, Yusof HM, Ho WY, Koh SP, et al. Antistress and antioxidant effects of virgin coconut oil in vivo. Exp Ther Med. 2015 Jan; 9(1):39-42. doi:10.3892/etm.2014.2045

14. Marina AM, Che man YB, Nazimah SAH, Amin I. Antioxidant capacity and phenolic acids of virgin coconut oil. Int J Food Sci Nutr. 2009; 60(supp12):114-23. doi:10.1080/09637480802549127

15. Illam SP, Narayanankutty A, Raghavamenon AC. Polyphenols of virgin coconut oil prevent pro-oxidant mediated cell death. Toxicol Mech Methods. 2017 Jul; 27(6):442-50. doi:10.1080/ 15376516.2017.1320458

16. Arunima S, Rajamohan T. Effect of virgin coconut oil enriched diet on the antioxidant status and paraoxonase 1 activity in ameliorating the oxidative stress in rats - a comparative study. Food Funct. 2013 Sep; 4(9):1402-9. doi:10.1039/c3fo60085h 
17. Famurewa AC, Nwankwo OE, Folawiyo AM, Igwe EC, Epete MA, Ufebe OG. Repeatedly heated palm kernel oil induces hyperlipidemia, atherogenic indices and hepatorenal toxicity in rats: beneficial role of virgin coconut oil supplementation. Acta Sci Pol Technol Aliment. 2017 Oct-Dec; 16(4):451-60. doi:10.17306/J.AFS.0513

18. Nevin KG, Rajamohan T. Beneficial effects of virgin coconut oil on lipid parameters and in vitro LDL oxidation. Clin Biochem. 2004 Sep; 37(9):830-5. doi:10.1016/j.clinbiochem.2004.04.010

19. Chinwong S, Chinwong D, Mangklabruks A. Daily consumption of virgin coconut oil increases high-density lipoprotein cholesterol levels in healthy volunteers: a randomized crossover trial. Evid Based Complement Alternat Med. 2017; 2017: 7251562. doi: 10.1155/2017/7251562

20. Cardoso DA, B Moreira AS, de Oliveira GMM, Raggio Luiz R, Rosa G. A coconut extra virgin oil-rich diet increases HDL cholesterol and decreases waist circumference and body mass in coronary artery disease patients. Nutr Hosp. 2015 Nov; 32(5):2144-52. doi:10.3305/ nh.2015.32.5.9642

21. Hu Yang I, De la Rubia Ortí JE, Selvi Sabater P, Sancho Castillo S, Julián Rochina M, Manresa Ramón N, et al. Coconut oil: nonalternative drug treatment against Alzheimer's disease. Nutr Hosp. 2015 Dec; 32(6):2822-7. doi:10.3305/nh.2015.32.6.9707

22. Council of Europe. European convention for the protection of vertebrate animals used for experimental and other scientific purposes. Eur Treaty Ser [Internet]. 1986 [cited 2017 Oct]. Available from: http://www.coe.int/en/web/conventions/full-list/-/conventions/ treaty/123.

23. Festing MFW, Altman DG. Guidelines for the design and statistical analysis of experiments using laboratory animals. ILAR J. 2002;43(4):244-58. doi:10.1093/ilar.43.4.244

24. Pekson R, Sia I. Acute and Subacute Toxicity of Virgin Coconut Oil (VCO) in Rodents. Manila; 2007.

25. Yunus WMM, Fen YW, Yee LM. Refractive index and fourier transform infrared spectra of virgin coconut oil and virgin olive oil. Am J Appl Sci. 2009; 6(2):328-31. doi:10.3844/ajassp.2009.328.331

26. Desamero MJM, Villablanca MA, Bariuan JV, Collantes T, Ang Gobonseng DT, Ang MJ, et al. Honey and propolis abrogate neurologic deficit and neuronal damage in the hippocampus and cerebral cortex of ischemic stroke rats. Int J Appl Res Nat Prod. 2017; 10(1):7-15.

27. Bederson JB, Pitts LH, Tsuji M, Nishimura MC, Davis RL, Bartkowski H. Rat middle cerebral artery occlusion: evaluation of the model and development of a neurologic examination. Stroke. 1986 MayJun;17(3):472-6. doi:10.1161/01.STR.17.3.472

28. Tang XN, Berman AE, Swanson RA, Yenari MA. Digitally quantifying cerebral hemorrhage using Photoshop ${ }^{\circledR}$ and Image J. J Neurosci Methods. 2010 Jul; 190(2):240-3. doi:10.1016/j. jneumeth.2010.05.004

29. Takagawa J, Zhang Y, Wong ML, Sievers RE, Kapasi NK, Wang $Y$, et al. Myocardial infarct size measurement in the mouse chronic infarction model: comparison of area- and length-based approaches. J Appl Physiol. 2007 Jun; 102(6):2104-11. doi:10.1152/ japplphysiol.00033.2007

30. McBride DW, Klebe D, Tang J, Zhang JH. Correcting for brain swelling's effects on infarct volume calculation after middle cerebral artery occlusion in rats. Transl Stroke Res. 2015 Aug; 6(4):323-38. doi:10.1007/s12975-015-0400-3

31. Bederson JB, Pitts LH, Germano SM, Nishimura MC, Davis RL, Bartkowski HM. Evaluation of 2,3,5-triphenyltetrazolium chloride as a stain for detection and quantification of experimental cerebral infarction in rats. Stroke. 1986 Nov-Dec; 17(6):1304-8. doi: 10.1161/01.str.17.6.1304.
32. Nakashima M, Niwa M, Iwai T, Uematsu T. Involvement of free radicals in cerebral vascular reperfusion injury evaluated in a transient focal cerebral ischemia model of rat. Free Radic Biol Med. 1999 Mar; 26(5-6):722-9. doi:10.1016/S0891-5849(98)00257-3

33. Fluri F, Schuhmann MK, Kleinschnitz C. Animal models of ischemic stroke and their application in clinical research. Drug Des Devel Ther. 2015 Jul; 9:3445-54. doi:10.2147/DDDT.S56071

34. Hennings LJ, Flores R, Roberson PK, Brown A, Lowery J, Borrelli $\mathrm{M}$, et al. Persistent penumbra in a rabbit stroke model: incidence and histologic characteristics. Stroke Res Treat. 2011; 2011:764830. doi:10.4061/2011/764830

35. Nogueira RG, Jadhav AP, Haussen DC, Bonafe A, Budzik RF, Bhuva P, et al. Thrombectomy 6 to 24 hours after stroke with a mismatch between deficit and infarct. N Engl J Med. 2018 Jan; 378(1): 11-21. doi:10.1056/NEJMoa1706442

36. Chan SC, Esther GE, Yip HL, Sugathan S, Chin PS. Effect of cold compressed coconut oil on cognition and behavior among patients with Alzheimer's disease - a pilot intervention study. Natl J Physiol Pharm Pharmacol. 2017; 7(12):1432-5. doi:10.5455/ njppp.2017.0829311082017

37. Melo IT, Rêgo EM, Bueno NB, Gomes TC, Oliveira SL, TrindadeFilho EM, et al. Ketogenic diet based on extra virgin coconut oil has no effects in young wistar rats with pilocarpine-induced epilepsy. Lipids. 2018 Feb; 53(2):251-4. doi:10.1002/lipd.12019

38. Rahim NS, Lim SM, Mani V, Abdul Majeed AB, Ramasamy K. Enhanced memory in Wistar rats by virgin coconut oil is associated with increased antioxidative, cholinergic activities and reduced oxidative stress. Pharm Biol. 2017 Dec; 55(1):825-32. doi:10.1080/ 13880209.2017.1280688

39. Mirzaei F, Khazaei M, Komaki A, Amiri I, Jalili C. Virgin coconut oil (VCO) by normalizing NLRP3 inflammasome showed potential neuroprotective effects in Amyloid- $\beta$ induced toxicity and highfat diet fed rat. Food Chem Toxicol. 2018 Aug; 118:68-83. doi:10.1016/ j.fct.2018.04.064

40. Da Silva DDC, Tavares MG, Do Nascimento CKB, Lira EC, Dos Santos AA, de Seixas Maia LMS, et al. Can coconut oil and treadmill exercise during the critical period of brain development ameliorate stress-related effects on anxiety-like behavior and episodiclike memory in young rats? Food Funct. 2018 Mar; 9(3):1492-9. doi:10.1039/c7fo01516j

41. Nafar F, Clarke JP, Mearow KM. Coconut oil protects cortical neurons from amyloid beta toxicity by enhancing signaling of cell survival pathways. Neurochem Int. 2017 May;105:64-79. doi:10.1016/ j.neuint.2017.01.008

42. Dávalos A, Alvarez-Sabín J, Castillo J, Díez-Tejedor E, Ferro $\mathrm{J}$, Martínez-Vila E, et al. Citicoline in the treatment of acute ischaemic stroke: an international, randomised, multicentre, placebocontrolled study (ICTUS trial). Lancet. 2012 Jul; 380(9839):349-57. doi:10.1016/S0140-6736(12)60813-7

43. Heiss W-D, Brainin M, Bornstein NM, Tuomilehto J, Hong Z. Cerebrolysin in patients with acute ischemic stroke in asia: results of a double-blind, placebo-controlled randomized trial. Stroke. 2012 Mar; 43(3):630-6. doi:10.1161/STROKEAHA.111.628537

44. Saver JL, Starkman S, Eckstein M, Stratton SJ, Pratt FD, Hamilton S, et al. Prehospital use of magnesium sulfate as neuroprotection in acute stroke. N Eng1 J Med. 2015 Feb; 372(6):528-36. doi:10.1056/NEJMoa1408827

45. Nasoohi S, Simani L, Khodagholi F, Nikseresht S, Faizi M, Naderi N. Coenzyme Q10 supplementation improves acute outcomes of stroke in rats pretreated with atorvastatin. Nutr Neurosci. 2019 Apr; 22(4):264-72. doi:10.1080/1028415X.2017.1376928 